\title{
CURRENT STATE OF COMPETITIVE INTELLIGENCE IN SOUTH AFRICA
}

\author{
Nisha Sewdass, Adeline Du Toit* \\ University of Pretoria Information Science, Lynwood Road, Pretoria 0002, South Africa \\ *Corresponding author. Tel.: +27 124206720; fax: +27 123625181. \\ E-mail address: adeline.dutoit@up.ac.za (A.D. Toit).
}

\section{Highlights}

- Competitive intelligence is a strategic management tool to enhance competitiveness.

- Questionnaires were sent to competitive intelligence professionals in South Africa.

- The majority of organisations indicated that competition in the South African business environment is very intense.

- Few South African organisations conduct competitive intelligence in a formal systematic manner.

\footnotetext{
Abstract

The economic success of a country depends on its capacity to apply activities which create a competitive advantage. The business environment is highly complex in South Africa and the purpose of this article is to examine the current situation with regard to competitive intelligence $(\mathrm{Cl})$ activities in South Africa. Since $\mathrm{Cl}$ is a relatively new activity in South Africa, this study is mainly exploratory in nature. A questionnaire survey methodology was used where questionnaires were administered to $\mathrm{Cl}$ experts in organisations in South Africa. The majority of respondents has postgraduate degrees and was in either top management or senior/middle management level of their organisations. Only 55\% of the respondents are of the opinion that they cope above average with changes in the business environment and $60 \%$ of the respondents strongly agreed that the most important $\mathrm{Cl}$ activity in their
} 
organisation is to use $\mathrm{Cl}$ to remain cognisant with government legislative trends. It is recommended that organisations should enhance a $\mathrm{Cl}$ culture by creating $\mathrm{Cl}$ awareness among employees and provide $\mathrm{Cl}$ training sessions for new employees.

\section{Introduction}

The economic success of a country depends on its capacity to apply activities which create a competitive advantage, its ability to create an environment of transformation and progress, and its capacity to innovate (Canongia, 2006: 58). Competitive intelligence $(\mathrm{Cl})$ has long been recognised as a strategic management tool that could enhance competitiveness.

The purpose of this article is to examine the current situation with regard to $\mathrm{Cl}$ activities in South Africa. The business environment is highly complex in South Africa because of factors such as the country's unique history, diversity, geography, political and institutional landscape. Companies tend to be less dynamic and more resistant to change, compared to companies in industrialised countries. Within a short period of time after the democratic elections in South Africa in April 1994, the international market opened up. South Africa as a net exporter of strategic minerals and the 'gateway' to Africa has an internal environment ideally suited to the use of $\mathrm{Cl}$ by companies to gain the competitive edge in a developing domestic economy and a challenging external environment. $\mathrm{Cl}$ is therefore enjoying increased prominence in South Africa. The limited information found on $\mathrm{Cl}$ activities in South Africa and the fact that the last comprehensive review of $\mathrm{Cl}$ activities in South Africa was conducted in 2001 led the authors to undertake this project.

The last survey to determine the implementation of $\mathrm{Cl}$ in South African companies was conducted in 2001 by Viviers, Saayman, Calof and Muller and since then no other data covering all the industries has been produced in this regard. There has been little quantitative empirical research on $\mathrm{Cl}$ in South Africa and the published quantitative research has been largely descriptive in nature, describing the distribution of $\mathrm{Cl}$ skills, resources and capabilities across organisations. In the past eleven years $\mathrm{Cl}$ has been a contemporary issue in South Africa and the business 
sector has realised the importance of Cl. Since 2001 many South African companies have made efforts to collect, analyse, disseminate and utilise information on the external environment. The number of companies with $\mathrm{Cl}$ units had risen noticeably. South African companies and the government now face the pressures associated with globalisation and they need to compete on a global level. Many companies in South Africa therefore established a Cl function since 2004 which they use for strategic and operational decision-making. The purpose of this article is to established whether a formalised $\mathrm{Cl}$ function is becoming an indispensable tool for decision-making in South African companies since this was not the situation in 2001 when Viviers and Muller conducted there research. Viviers et al. (2002:53-67) also found that few universities in South Africa offered $\mathrm{Cl}$ training. $\mathrm{Cl}$ training is now offered by at undergraduate and postgraduate level by the University of Johannesburg and the University of Pretoria and more $\mathrm{Cl}$ professionals are entering the market. Because of this, $\mathrm{Cl}$ practices have become more sophisticated since 2001.

\section{Competitiveness in the global economy}

Competitiveness is a multifaceted concept and according to Schuller and Libom (2009: 935) competitiveness refers to the competitive environment that a country's companies face. According to Waheeduzzaman (2002:13) the ultimate goal of competitiveness is to improve the standard of living or real income of the citizens of a country. Since companies actually compete in the global economy, many authors are of the opinion that when studying competitiveness, the focus should be on companies since they are the main engines of a country's competitiveness (Garelli, 2003: 704). For a country to achieve higher international competitiveness, companies should produce products at lower costs and higher quality (Arslan \& Tathdil, 2012: 34). As globalisation increases, it has serious implications for developing countries (Williams \& Morgan, 2010: 27) since the growing interdependencies between national economies accelerate the process of economic integration in the knowledge economy (Postelnicu \& Ban, 2010: 54). Porter (1990:25-40) developed the diamond model of competitiveness that helps people to understand the competitive position of a country in the global economy. He identifies four classes of country attributes (which he calls the national diamond) that provide the underlying conditions or platform for the determination of the national competitive 
advantage of a nation. These are factor conditions, demand conditions, related and support industries, and company strategy, structure and rivalry. He also proposes two other factors, namely government policy and chance (exogenous shocks), that support and complement the system of national competitiveness but do not create lasting competitive advantages. Porter's (1990) diamond framework thus provides the link between company and country-specific sources of competitive advantage that companies leverage to gain international competitive advantage.

With the globalisation of markets, the need to enhance companies' and countries' competitiveness has grown rapidly. If government supports and encourage the application of $\mathrm{Cl}$, then it would have a more positive impact on the economy of a country and the quality of the lives of citizens. For these reasons, it has become a matter of survival for many South African companies to extensively globalise their business activities.

\section{Competitive intelligence}

$\mathrm{Cl}$ is the component of business intelligence aimed at gaining strategic advantage (Porter, 1980: 15). It includes competitor intelligence as well as intelligence collected on customer, suppliers, technologies, environments, or potential business relationships (Gilad, 1989: 30). As companies compete in the global economy, the need for $\mathrm{Cl}$ in a global context becomes essential for further success. Companies in developing countries (like South Africa) who are familiar with $\mathrm{Cl}$ practices in their local regional markets may find the requirement to extend $\mathrm{Cl}$ practices globally very difficult to accomplish in a structured way (James, 2000: 44). The basis for $\mathrm{Cl}$ is knowing the difference between information and intelligence. Executives usually have to read through several reports and proposals before making decisions, and it is often found that they are overwhelmed with information and lack intelligence that will enable them to make more efficient decisions. Therefore, it can be said that the companies that are able to turn information into intelligence will succeed (Sewdass, 2012:24). Cl is the process of developing actionable foresight regarding competitive dynamics and nonmarket factors that can be used to enhance competitive advantage. $\mathrm{Cl}$ is concerned with the techniques used to select and filter information from a variety of sources, to interpret and analyse it, to communicate it to the right people and to use it effectively. Competitive dynamics refers to the evolution of a company's industry and the moves 
and countermoves of competitors, suppliers, customers, alliance partners and potential competitors. Non-market factors such as government regulation, tariffs and the culture of a country impact competitive dynamics but are not suppliers of products or services to the industry (Prescot, 1999:42-43). However, non-market factors can provide early warning of threats and opportunities that affect the strategies of companies (Fleisher, 1999: 25). Cl uses legally and ethically public sources to assess the strengths and weaknesses of its competitors.

According to Calof and Skinner (1999:1) a country will under-perform without an appropriate $\mathrm{Cl}$ infrastructure and they quote Prescott and Gibbons by stating that "the key question is not whether governments should play a role in a company's $\mathrm{Cl}$ efforts but what should be the purposes and methods used by government." Countries such as France, Sweden, Japan and Canada have recognised the value of government and industry working jointly in the development of an intelligence culture (Calof \& Skinner, 1999:3).

The new paradigm in development economics is based on self-analysis, self-reliance and self-renewal, which would seem to necessitate a development-orientated intelligence policy in a country. Currently most developing countries are weakly integrated with the global economy. For companies to compete globally they are facing many challenges since consumers use the Internet to compare products and prices and they need to stay ahead of their competitors. If this situation is to change, major infrastructural investment in information systems and services, as well as technical training, is required. Utilising $\mathrm{Cl}$ will enable companies in developing companies to gain a greater market share and to compete successfully against international competitors (Pellissier \& Kruger, 2011).

Ifan, Dou, Manullang and Dou (2004:995) state that "after a period of recession and inflation, most developing countries have to face the necessity of improving their capacities to innovate and increase the competitiveness of their industries." Furthermore, in developing countries, the creation of new products from their natural resources is important as it has the ability to contribute to the country's foreign direct investment (FDI) (Dou, Dou \& Manullang, 2005). In order to achieve this, the implementation of $\mathrm{Cl}$ will be the answer. 


\section{South African situation with regard to competitiveness}

South Africa faces new socio-economic challenges and research capacity needs to be developed in the context of the global economy. Before 1994 South Africa was isolated from the rest of the world as a result of the apartheid regime and this inhibited competitiveness (Viviers \& Muller, 2004:54). The use of $\mathrm{Cl}$ before 1994 has mostly negative connotations since South African intelligence activities were mostly pursued by state institutions. Because of isolation information about scientific and technological innovations developed in South Africa was disseminated through academic and technological journals, conferences and trade shows. Public intelligence in South Africa has influenced $\mathrm{Cl}$ in South Africa in several important ways. Many of the first generation $\mathrm{Cl}$ professionals in South Africa came from the National Intelligence Service and government organisations and the majority of $\mathrm{Cl}$ consultants in South Africa were before 1994 employed by the National Intelligence Service. After 1994 the economy became more open and, along with export markets, domestic markets became increasingly larger and more competitive with increased globalisation of markets.. Since the domestic market was relatively small, the government pushed to increase exports for further economic development. Many industries were deregulated and privatised and there was a large construction boom due to the 2010 Soccer World Cup. To survive many South African companies needed to extensively globalise their business activities to exploit country differences and worldwide markets. This prompted companies to become more sensitive to external environments which includes monitoring political/legal, economic, technological, socio-cultural and industry forces such as competitors, customers and suppliers. Information technologies were integrated into $\mathrm{Cl}$ extensively for collecting public information and reliance on global information also became higher with increased globalisation.

According to the Global Competitiveness Report (Schwab, 2011: 39) sub-Saharan Africa has grown rapidly over the past 15 years and some African countries have improved their national competitiveness. South Africa has moved up by four places to attain the $50^{\text {th }}$ position in terms of competitiveness among 142 countries and it remains the highest ranked country in sub-Saharan Africa and second-places among the BRICS economies. As a developing country South Africa has many challenges such as skills shortages and increasing its competitiveness. 
By regional standards, South Africa also benefits from the size of its economy and it ranked $25^{\text {th }}$ in the market size. The country's financial market development is ranked $4^{\text {th }}$ and this indicates that there is a very high level of confidence and trust in South Africa's financial markets in other parts of the world. South Africa does reasonable well in areas such as business sophistication $\left(38^{\text {th }}\right)$ and innovation $\left(41^{\text {st }}\right)$. These are a few examples that indicate that South Africa is the most competitive economy in the region but in order to further enhance its competitiveness, the country will need to address the most problematic factors for doing business. Inefficient government bureaucracy, inadequately educated workforce, restrictive labour regulations and corruption in South Africa are the most critical areas that pose problems for other countries doing business with South Africa.

In the previous survey of Cl activities in South Africa (Viviers \& Muller, 2002: 53-67) South African companies did not conduct good intelligence practices and showed a lack of appropriate structures for $\mathrm{Cl}$. Few companies had $\mathrm{Cl}$ units and used $\mathrm{Cl}$ systems. Companies spent time to collect information but did not analyse the information.

\section{Research methodology}

Since $\mathrm{Cl}$ is a relatively new activity in South Africa, this study is mainly exploratory in nature. A questionnaire survey methodology was used where questionnaires were administered to $\mathrm{Cl}$ professionals in organisations in South Africa. The organisations surveyed for the study were based on the Standard Industrial Classification that is used worldwide by government to classify statistics and comprises of ten categories. An additional category, oil and gas industry was added. Hence the industry classification used in the study was as follows:

- Agriculture, hunting, forestry and fishing industry

- Mining and quarrying industry

- Manufacturing industry

- Electricity, gas and water supply industry

- Construction industry

- Wholesale and retail trade industry

- Tourism industry 
- Transport, storage and communication industry

- Financial, insurance, real estate and business services

- Community, social and personal services

- Oil and gas industry

A combination of convenience sampling and snowball sampling were used to identify the experts in $\mathrm{Cl}$ in these industries. Convenience sampling refers to the procedure of obtaining respondents (units or people) who are most conveniently available (Zikmund, 1994:367). Snowball sampling, on the other hand, refers to procedures in which additional respondents are obtained from information provided by initial respondents. This technique is used to locate members of rare populations by referrals (Cooper \& Schindler, 2007:425). Cl practices in South Africa are still in the early phase of development and when $\mathrm{Cl}$ is practiced by individuals in organisations, it is still a matter of sensitivity (Strauss \& Du Toit, 2010: 311; Decaup \& Domingues, 2009: 25). Furthermore, in South Africa there is no recognized list of practicing $\mathrm{Cl}$ professionals available (Viviers \& Muller, 2004:56). Thus the researchers had to rely on their personal contacts and networks in industries to identify the $\mathrm{Cl}$ professionals in each organisation. They were the experts assumed to have a sound knowledge of $\mathrm{Cl}$, its implementation and benefits for organisations. The snowball sampling technique was then applied, where the respondents of the convenience sampling technique, were asked for references of other respondents who would possibly complete the questionnaire. This is perhaps a limitation of this study as some important experts practicing $\mathrm{Cl}$ could possibly be left out of the survey. The questionnaire was self-constructed and was based on all the elements of the $\mathrm{Cl}$ processes.

The questionnaire was structured as follows:

- Section A: Background and demographic information

- Section B: Competitive situation in organisations

- Section C: Competitive intelligence implementation in organisations.

The questionnaire was sent as an attachment via email and it was accompanied by a cover letter to all identified respondents. The completed questionnaires had to be 
returned to the email of the researchers. The questionnaires were emailed to $40 \mathrm{Cl}$ experts and 24 questionnaires were completed which represents a response rate of $60 \%$.

\section{Analysis and discussion of findings}

\subsection{Biographical data}

The gender of the respondents was mostly male (70\%) and $50 \%$ of the respondents were younger than 50 years. The majority of respondents has postgraduate degrees and was in either top management or senior/middle management level of their organisations (85\%). These findings correlate with the findings of Du Toit and Strauss (2010:24). This refers to the factor determinant of Porter's diamond framework. Only $50 \%$ of the respondents were employed by companies with more than 500 employees. Interesting is that four companies with less than 50 companies also use $\mathrm{Cl}$ as a strategic tool.

\subsection{Competitive situation}

Although the majority of South African organisations indicated that competition in their business environment is very intense (65\%), only $55 \%$ of the respondents are of the opinion that they cope above average with changes in the business environment. This is an indication that organisations in South Africa should pay more attention to $\mathrm{Cl}$ as a strategic business tool and refers to the company strategy, structure and rivalry determinant of Porter's diamond framework.

According to the majority of respondents in South Africa (60\%), a formal $\mathrm{Cl}$ function does exist in their organisation and the $\mathrm{Cl}$ function has been in existence for more than five years in $65 \%$ of the companies.

\subsection{Industry representation}

According to Figure 1 the majority of the respondents (25\%) were from financial, insurance, real estate and business services, while $15 \%$ of the respondents were in the agriculture, hunting, forestry and fishing industry and $10 \%$ of the respondents in either the electricity and water supply industry or the tourism industry or the oil and gas industry. This is an indication of the industries where competition is very intensive and the major companies in these industries such as all the retail banks 
and insurance companies, Eskom, Sasol do have $\mathrm{Cl}$ units. Interesting $10 \%$ of the respondents were from the related and support industries determinant of Porter's diamond framework.

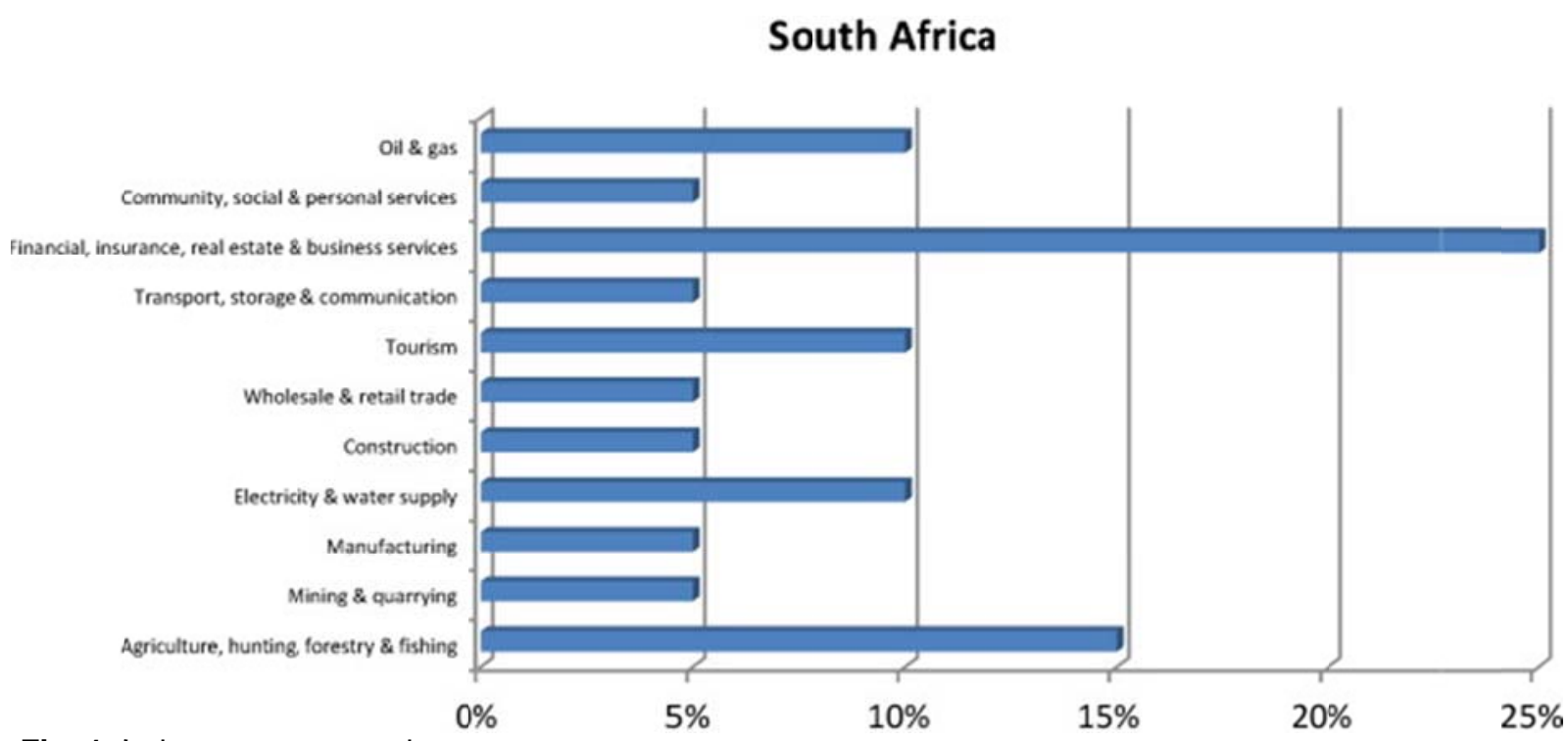

Fig. 1. Industry representation.

\section{$6.4 \quad$ Cl activities}

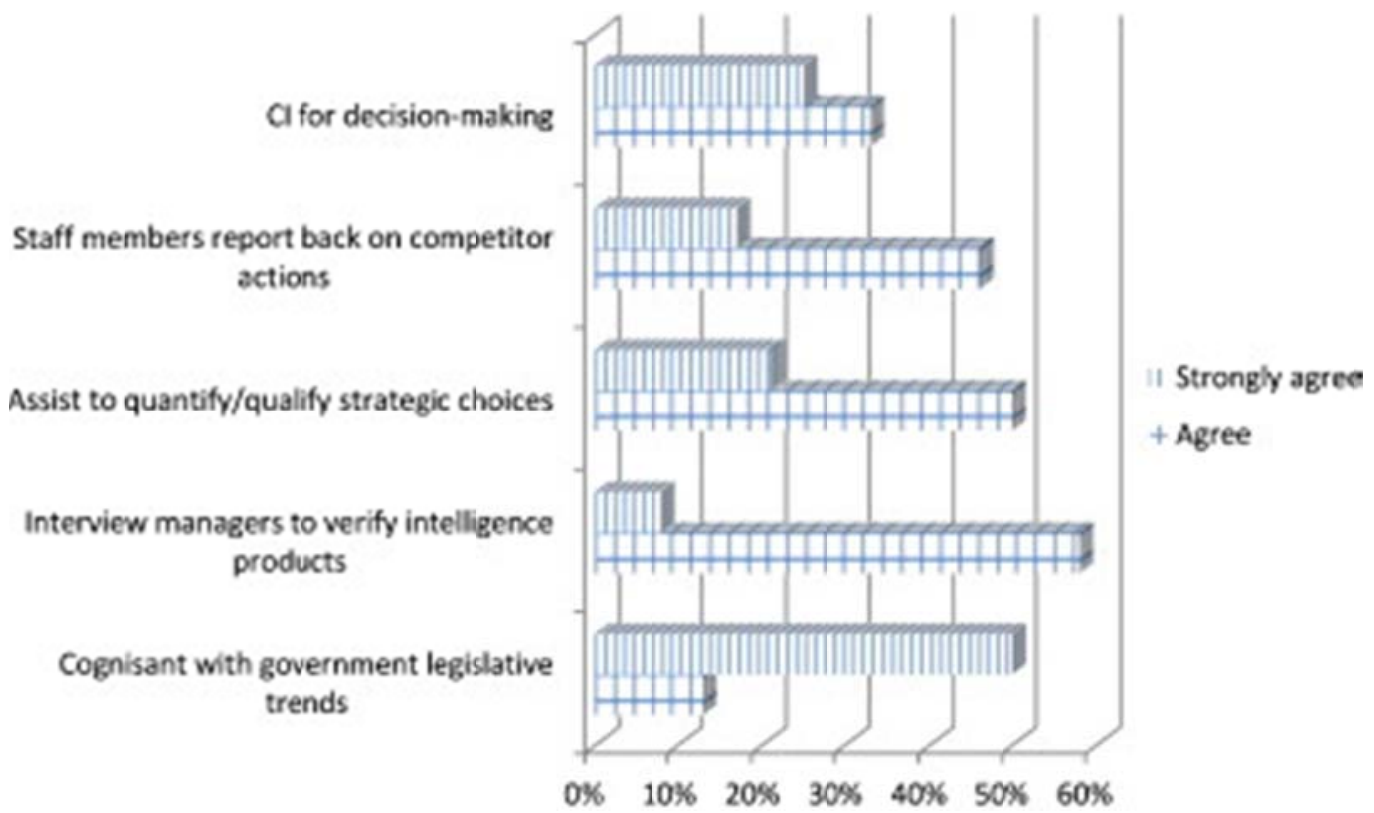

Fig. 2. Five most important $\mathrm{Cl}$ activities. 
According to Figure 2, 50\% of the respondents strongly agreed that the most important $\mathrm{Cl}$ activity in their organisation is to use $\mathrm{Cl}$ to remain cognisant with government legislative trends while $25 \%$ of the respondent strongly agreed that they use Cl for decision-making. This confirms what Viviers et al. (2002: 30) has stated that one of the major $\mathrm{Cl}$ activities are regulatory matters. Twenty-one percent of the respondents use $\mathrm{Cl}$ to assist in the quantification/qualification of strategic choices. This is an indication of the maturity level of $\mathrm{Cl}$ in South Africa.

\subsection{Use of secondary sources}

The most important secondary source used by South African organisations are information on regulatory bodies (see Figure 3). The fact that information on regulatory bodies is so important, is an indication that restrictive regulations (enacted by the government) often contribute to a decline in competitiveness. This is in contrast with developed countries where deregulation enhances competitiveness. However, according to Fleisher (1999: 28) Cl allows decision makers to take appropriate action to defeat legislation or regulation. Promotional material, internal financial information and corporate websites are also important sources.

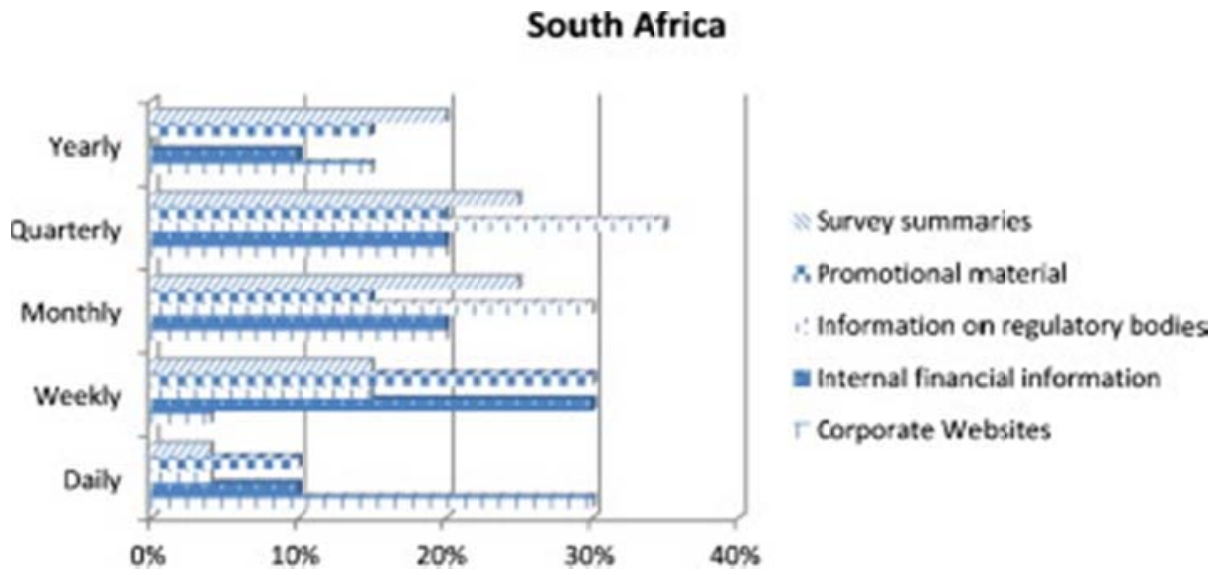

Fig. 3. Use of secondary sources.

\subsection{Use of primary sources}

The most important primary sources used by organisations in South Africa are industry experts, direct customer feedback and company employees. Staff who attend conferences and seminars are also important information sources. This indicates that South African organisations sensitize and train their employees to 
collect information on the competitive environment (see Figure 4). The results of the study conducted by De Pelsmacker, Muller, Viviers, Saayman and Cuyvers (2005: 610) reveal a similarity in that primary sources are an important source of information for $\mathrm{Cl}$ professionals.

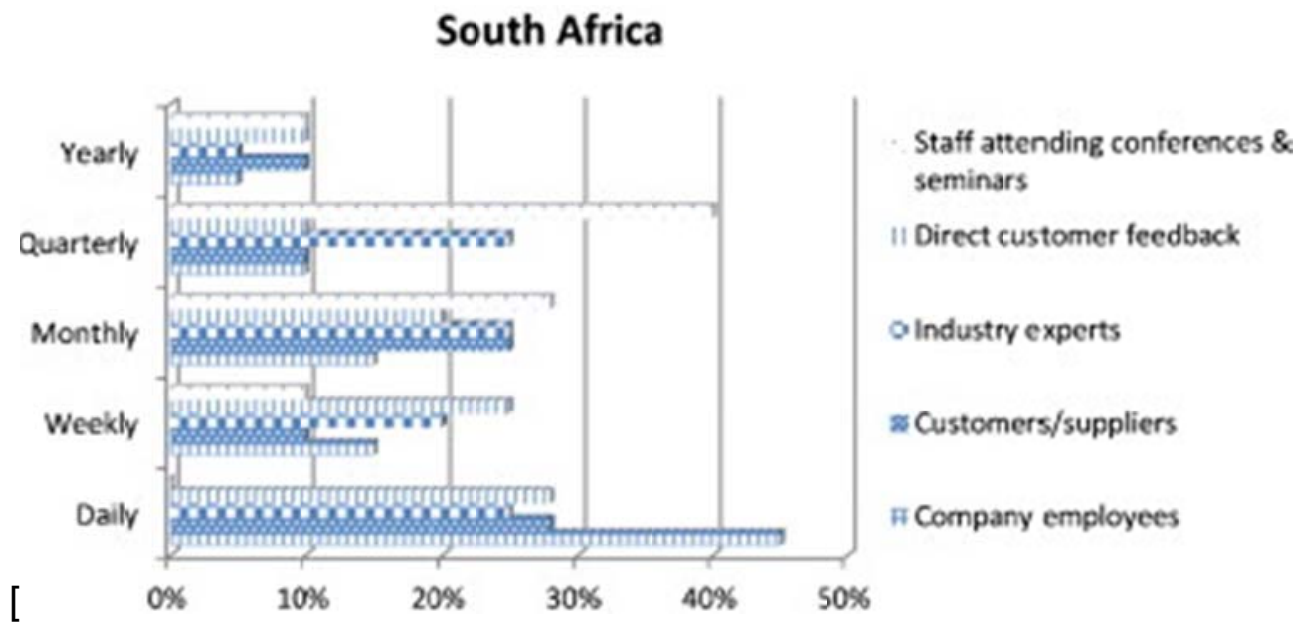

Fig. 4. Use of primary sources.

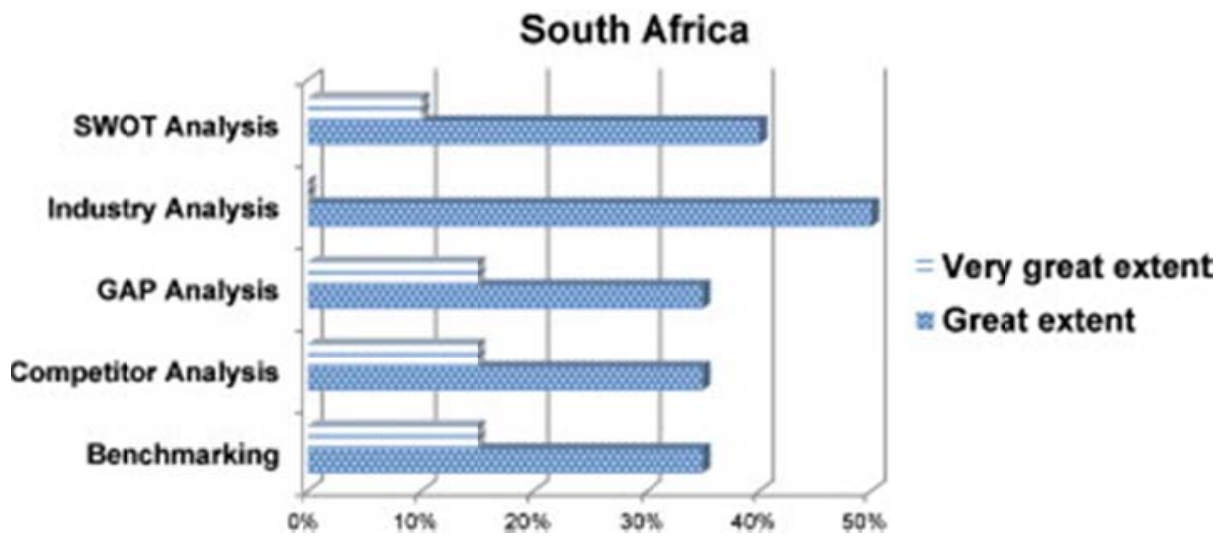

Fig. 5. Most important analytical methods or models used.

\subsection{Cl Analytical methods or models used}

With regard to the use of $\mathrm{Cl}$ analytical methods or models, $50 \%$ of the respondents used industry analysis to a great extent while $40 \%$ of the organisations used SWOT analysis to a great extent and $10 \%$ of the organisations used it to a very great extent (see Figure 5). Benchmarking, competitor analysis and GAP analysis is used to a great extent by $35 \%$ of the organisations and $15 \%$ used it to a very great extent (see 
Figure 5). This collaborates with the findings of Viviers and Muller (2004:64) that South African organisations do not use sophisticated analysis techniques.

\subsection{Methods used to distribute and present CI findings}

The most popular method to distribute $\mathrm{Cl}$ findings in South Africa is presentations which are used by $41 \%$ of the organisations to a great extent and by $27 \%$ of the organisations to a very great extent. Briefings are used by $55 \%$ of the organisations to a great extent and by $14 \%$ of the organisations to a very great extent. This is also an indication that $\mathrm{Cl}$ is practiced on a mature level in South Africa. Email is used by $27 \%$ of the organisations to a very great extent, personal delivery by $23 \%$ of the organisations to a very great extent and reports are used by $45 \%$ of the organisations to a great extent (see Figure 6).

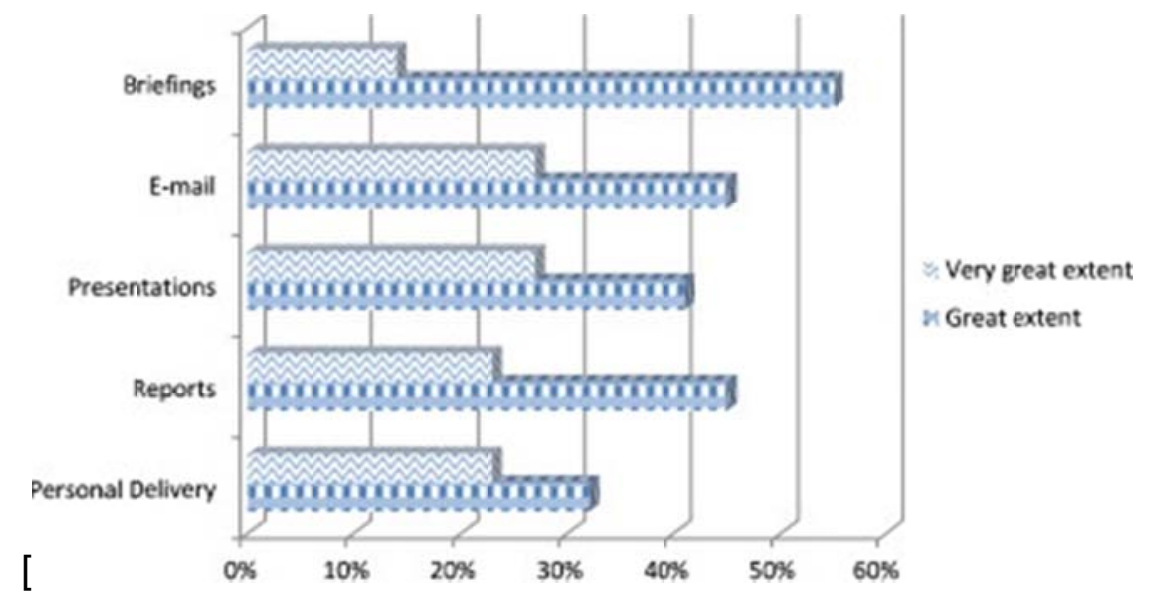

Fig. 6. Methods used to distribute \& present $\mathrm{Cl}$ findings.

Conclusion and recommendations

South Africa as a country continues to rank low in the world of competitiveness. The research done for this article focused on the need for South African organisations to perceive $\mathrm{Cl}$ as one of the most important tools to improve their competitiveness.

As South Africa becomes more integrated into the global economy it stands to reason that the global economy will have more of an impact 
on the country's economy. To this end it has become more crucial to monitor global events and trends and it is very important for the country to develop a $\mathrm{Cl}$ culture. $\mathrm{Cl}$ analyses not just the environment but competitors and markets as well. Therefore understanding the direction that competitors are moving to in the future is key to be able to counteract them timeously. Keeping abreast of domestic and international market trends and their potential impact on organisations is vital. Trend tracking needs to monitor the impact of not only product changes but also organisational changes such as future mergers and dissolutions. It is also recommended that South African organisations should enhance a $\mathrm{Cl}$ culture by creating $\mathrm{Cl}$ awareness among employees and provide $\mathrm{Cl}$ training sessions for new employees. Cl staff in these organisations should be trained in and afforded the opportunity to gain experience in engaging with groups of senior management in debate/dialogue as opposed to delivering reports or engaging in one-on-one briefings.

South Africa should strive to achieve higher standards of living for the citizens by using $\mathrm{Cl}$ techniques to improve the information and communications technology infrastructure. $\mathrm{Cl}$ professionals in the private industry should therefore collaborate with their colleagues in government. If this happens, an increasing number of small and medium sized companies will use $\mathrm{Cl}$ to gain a competitive advantage.

$\mathrm{Cl}$ as one of the fastest growing domains has long been acknowledged as a strategic management tool and if used in strategic decision-making, could enhance the competitiveness of South African organisations in the global economy. There is clear recognition that the world will become more competitive and will increasingly do so. Whether South African managers will meet these challenges is not clear and according to the empirical survey conducted, few have actual plans to improve their ability to keep track of competitors and to enhance their competitiveness. There appears to be a degree of complacency and self-deception that is inhibiting managers from instigating effective planning to improve $\mathrm{Cl}$ and few conduct $\mathrm{Cl}$ in a formal systematic manner. 


\section{REFERENCES}

Arslan, N. \& Tathdil, H. (2012). Defining and measuring competitiveness: a comparative analysis of Turkey with 11 potential rivals. International Journal of Basic \& Applied Sciences, 12(2): 31-43.

Calof, J. \& Skinner, B. (1999). Government's role in competitive intelligence: what's happening in Canada? Competitive Intelligence Magazine, 2(2), 1-5.

Canongia, C. (2006). Synergy between competitive intelligence (Cl), knowledge management (KM) and technological foresight (TF) as a strategic model of prospecting - the use of biotechnology in the development of drugs against breast cancer, Biotechnology Advances, 25, 57-74.

Cooper, D.R. \& Schindler, P.S. (2007). Business research methods. $9^{\text {th }}$ ed. New York: McGraw-Hill.

Decaup, A. \& Domingues, F. (2009). Competitive intelligence practices implementation in Brazilian companies, Competitive Intelligence Magazine, 12(3), 20-25.

De Pelsmacker, P., Muller, M-L., Viviers, W., Saayman, A. \& Cuyvers, L. (2005). Competitive intelligence practices of South African and Belgian exporters. Marketing Intelligence \& Planning, 23(6): 606-620.

Dou, H., Dou Jr., J.M., \& Manullang, S.D. (2005). The magic triangle - how to develop and apply competitive intelligence in developing countries. [Online]. Available: http://isdm.univ-tln.fr/PDF/isdm22/isdm22 dou.pdf. Accessed February 2012.

Du Toit, A.S.A. \& Strauss, A.C. (2010). Competitive intelligence and Africa's competitiveness: what's happening in South Africa? Mousaion, 28(2), 17-32.

Fleisher, C.S. 1999. Public policy competitive intelligence. Competitive Intelligence Review, 10(2): 23-36.

Garelli, S. (2003). Competitiveness of nations: the fundamentals, in IMD World Competitiveness Yearbook: 702-713. [Online]. Available:

http://www.imd.org/research/publications/wcy/index.cfm. Accessed January 2013. 
Gilad, B. (1989). The role of organized competitive intelligence in corporate strategy. Columbia Journal of World Business, 24, 29-35.

Ifan, H-K., Dou, J-M., Manullang, S. and Dou, H. (2004). Developing competitive technical intelligence in Indonesia, Technovation, 24, 995-999.

James, S. (2000). Focus on global competitive intelligence, Information Outlook, $4(2), 43-46$.

Pellissier, R. \& Kruger, J.P. (2011). Understanding the use of strategic intelligence as a strategic management tool in the long-term insurance industry in South Africa, South African Journal of Information Management, 13(1). [Online]. Available: www.sajim.co.za. Accessed January 2013.

Porter, M.E. (1980). Competitive Strategy: Techniques of Analyzing Industries and Competitors. New York: The Free Press.

Porter, M.E. (1990). The Competitive Advantage of Nations. New York: MacMillan.

Postelnicu, C. \& Ban, I.M. (2010). Some empirical approaches of the competitiveness' diamond - the case of Romanian economy. The Romanian Economic Journal, 13(36): 53-77.

Prescot, J.E. (1999). The evolution of competitive intelligence - designing a process for action, Proposal Management, Spring, 37-52.

Schuller, B.J. \& Lidbom, M. (2009). Competitiveness of nations in the global economy. Economics \& Management, 14: 934-939.

Schwab, K. (ed). (2011). Global competitiveness report 2011-2012. Geneva: World Economic Forum.

Sewdass, N. (2012). Proposing a competitive intelligence (Cl) framework for public service departments to enhance service delivery, South African Journal of Information Management, 14(1). [Online]. Available: www.sajim.co.za. Accessed June 2012.

Strauss, A.C. \& Du Toit, A.S.A. (2010). Competitive intelligence skills needed to enhance South Africa's competitiveness, Aslib Proceedings, 62(3), 302-320. 
Vivers, W., Saayman, A., Calof, J.L \& Muller, M-L. 2002. Competitive intelligence practices: a South African study. South African Journal of Business Management,

33(3): 27-37.

Viviers, W. \& Muller, M-L. (2004). The evolution of competitive intelligence in South Africa: early 1980s - 2003, Journal of Competitive Intelligence and Management, 2(2), 53-67.

Waheeduzzaman, A.N.M. (2002). Competitiveness, human development and inequality: a cross-national comparative inquiry, Competitiveness Review, 12(2), 1317.

Zikmund, W.G. (2003). Business research methods. $7^{\text {th }}$ ed. Mason: South Western Thomson.

Dr Nisha Sewdass is a senior lecturer in the Department of Information Science at the University of Pretoria, South Africa. She has presented 22 papers at conferences and published six articles in peer-reviewed journals. She is on the editorial board of the South African Journal of Information Management.

Prof Adeline du Toit is an extraordinary professor in the Department of Information Science at the University of Pretoria, South Africa. She has published 77 peerreviewed articles, six chapters in books and presented papers at 37 international conferences. She is on the editorial board of six international journals. 